\title{
A Concise Note on Risk Externalities: A Critical Review
}

\author{
Emmanuel Senyo Fianu
}

Faculty of Economics and Business, Leuphana University of Lüneburg, Germany

Copyright (C) 2017 by authors, all rights reserved. Authors agree that this article remains permanently open access under the terms of the Creative Commons Attribution License 4.0 International License

\begin{abstract}
This paper provides a review of the (risk) externality literature with the aim of identifying risk externalities arising from various interactions in the economics of environmental protection. In addition, various classification of externalities that exist have been explored. It highlights how such externalities might depend on the characteristics of economic interactions coupled with their impacts. The findings of this paper show that risk externalities result from risk mitigation and reduction activities, thereby, having varying degrees of impacts, and inducing inefficiency in economic systems. In addition, empirical investigations in the context of (risk) externalities have been provided.
\end{abstract}

Keywords (Risk) Externalities, Valuation Methods, Regulations

JEL-Classification: Q54, H23, H41

\section{Introduction}

Externalities have been an issue in different sectors of the economy for several decades. However, it is very difficult for researchers to reach an agreement on a unifying and precise definition of what externalities mean, making many authors to use the term to suit their focal viewpoints. Because of this, some authors have used it in a way that encompasses all forms of market failures. Baumol and Oates (1988) and the references therein, provide a broad overview on the topic of externalities. As presented by these authors, externalities occur (i) when an action of an economic agent affects the utility or production possibilities of another agent. (ii) when the welfare of an agent is dependent on the activities of some other agent, and (iii) when an agent does not carry all the consequences of his or her actions. That is to say, externalities exist, when there is no full compensation concerning a damage due to the effect of externalities.

With a full compensation of the damage, then the externalities do not exist, at least contingent on the extent to which compensations have been paid, see Sundqvist (2004) for a brief overview. Under these circumstances, the externalities are said to be internalised. In other words, externalities exist, when not all economic activities are reflected in market transactions. Generally speaking, an externality is the unaccounted side-effect of an agent's action or behaviour influencing another agent's welfare, which could threaten even her existence. The studies of the topic of externality mostly hinges on the fact that an externality will in one way or the other influence utility and hence, the welfare of agents or individuals. Because of this, the concept of externality has a theoretical underpinning in neoclassical welfare economics. Thus, externalities lead to market failures that violates the First Theorem of Welfare Economics, for instance, private markets will fail to achieve Pareto optimality, (see Varian (1992) for a brief overview).

Several types of externalities exist, which are mostly influenced by their impact and origin. According to Owen (2004), the origin of an externality is typically the absence of fully defined and enforceable property rights. However, correcting this situation through establishing such rights is not always an easy task. In such circumstances, at least in theory, the appropriate rectifying device is a Pigouvian tax equal to marginal social damage levied on the generator of the externality. Bhattacharyya (2011) in his book presents the following classifications: (a) positive/negative externality, which is, when an externality provides net benefits to others. In this case, it is considered a positive externality. For instance, scenic beauty as well a pleasant odour of flowers of plants in a private garden provides an external economy to all who pass by or around it. On the other hand, discomfort from smoking cigarettes to non-smokers is an example of negative externality; (b) private (depletable)/public (undepletable) externality: The differentiation between these externalities relies on the idea of jointedness of supply with respect to the externality. In this domain, if an external effect is such that consumption by an economic actor leaves no external effect for other economic actors, then the effect is considered as private or depletable. For example, if one dumps a trash in ones neighbour's backyard, it is unlikely to be dumped somewhere else and therefore, it is depleted. This kind of private externality is limited in nature. The non-depletable externalities are direct opposite to the depletable externalities.

Most of the environmental externalities are public in nature and hence, non-depletable. This simply, implies that 
the availability of an externality to a particular entity does not preclude and reduce its availability to others; (c) pecuniary/technological externalities, which is a specific type of externality that arises from a change in the prices of inputs or outputs in the economy. This lies in the fact that the production of this type of externality requires other commodities for its production. In particular, oil as a commodity can be used in the production of electricity. Thus, an increase in oil prices in the international market leads to an increase in electricity prices. The consumers of electricity are affected and they suffer negative external effects. However, unlike a true externality, this oil price effect does not change the technical relationship of electricity production. Once the oil price effect is withdrawn, the old position could be reached. A technological externality on the other affects the input-output relationships. Zerrahn (2017) provides a survey of wind power and externalities from various perspectives, investigating the economic rationale behind global wind power deployment. This is to mitigate negative externalities of conventional electricity technologies, specifically, emissions from fossil fuel. Wind turbines entails externalities in that it can lower quality of human life through noise and visual impacts, and threaten wildlife. On the other hand, variable wind electricity leads to additional costs within electricity systems.

From a different perspective, Chipman and Tian (2012) analyze a simple model of two agents - a polluter and a pollutee-and two commodities: "money", which stands for an exchangeable private good desired by both agents and pollution, which is a public commodity desired by the polluter but undesired by the pollutee. The effect of the externality makes these authors refer to it as a detrimental externality. In their paper, Alonso-Carrera et al. (2004) analyze the welfare properties of the competitive equilibrium of an economy with capital accumulation; they assumed that preferences vary over time due to the existence of a process of habit formation and consumption spillovers. They argue that individuals will not derive utility from their absolute level of consumption at a given period, rather, from the difference between consumption and a reference point. In their opinion, this departure from the more traditional formulations of preferences has consequences for the dynamic behaviour of both consumption and capital, thereby, giving rise to consumption externalities. In effect, individual preferences also exhibit consumption externalities that affect both the individual's utility level and the marginal utility of individual consumption. Also, Liu and Turnovsky (2005) analyze the effects of consumption in addition to production externalities on capital accumulation. They show that the importance of consumption externalities depends upon the elasticity of labour supply. That is, if the labour supply is inelastic, consumption externalities cause no long-run distortions. However, whether there are distortions along the transitional path depends upon consumer preferences.

Moreover, the effects of production externalities according to these authors are more pervasive; they exert long-run distortionary effects irrespective of labour supply. A similar analysis can be found in Turnovsky and Monteiro (2007).
Other related literature, which dealt with consumption externalities include Lünberger (1995), Dupor and Liu (2003), Huang and Tzeng (2008). Some recent studies on (risk) externalities include the following : Capitanio et al. (2014), Baumgärtner and Fianu (2015), Hayes (2016), Andres et al. (2017) and many more. All the above literature and the references therein, reconfirm the fact the name of externality under consideration depends on the process that give rise to it. Therefore, one could talk of knowledge externalities, traffic externalities, health externalities, environmental externalities and many more as some of the types of externatlities that exist. The focus of this paper is to explore the concept of risk externality, which is an underlying effect of most externalities in the literature. In effect, this paper contributes to the literature in the following ways: First, it identifies various (risk) externalities due to economic interactions and explore their classifications that exists. Secondly, it provides the epistemological dimension of knowledge concerning (risk) externalities coupled with empirical investigations and deliberations with recommendation for further research, which could be useful for making policy decisions in the long-run. This paper, therefore, highlights the fact that risk externalities result from risk mitigation and reduction activities, thereby, having varying degrees of impacts, and inducing inefficiency in economic systems.

The subsequent sections proceed as follows: Section 2 provides a detailed discussion on risk externalities. However, in section 3, various valuation methods have been examined. Section 4 surveys and highlights the emerging empirical methodologies, which are useful in studying real-life episodes of externalities and section 5 provides some concluding remark.

\section{Risk externalities}

The concept of externality transcends various disciplines of study as well as various sectors of an economy. Some of these sectors and disciplines include the transportation, the financial sector and many others. Nevertheless, I argue that the concept of risk externality, which is the focus of this section, is an underlying externality of various externality, especially, when, there is a risk dimension to the economic actors involved. Shafran (2008) highlights the fact that homeowners living in the wildland-urban interface must decide whether to create a defensible space around their house in order to mitigate the risk of a wildfire destroying their home. This implies that the externality under investigation in this context is risk externality. That is, the risk that one homeowner faces depend on the risk mitigation decisions of neighboring homeowners.

One consequence of risk externalities according to the author is that homeowners will invest in sub-optimal amounts of defensible space since they fail to internalize all of the benefits of defensible space. In addition, Taylor et al. (2013) explore homeowners' incentives to invest in defensible space using a unique data set on 35 WUI communities in Nevada. However, they find no evidence to suggest that homeowners 
systematically misjudge their wildfire risk, though they do find evidence of strategic complementarities in defensible space investments due to risk externalities in certain communities, depending on predominant vegetation.

In addition, Delpierre et al. (2016) point out that risksharing in small groups entails negative risk externalities and moral hazard. In effect, risk externalities lead to moral hazards in their analytical framework, where they examine the vulnerabilities of poor farmers to income shock in their bid to adopt high risk/return technologies as compared to rich farmers. Conversation activities can generate externalities, especially, depending on whether landowners are dedicated to it or not. Choi et al. (2017), in their paper, examine a conservation procurement auction with bidirectional externalities in which, conservation output can affect the costs of individuals dedicated to market production, and vice versa. Thus, ignoring the presence of externalities could affect procurement activities negatively. Due to the pervasive nature of bidirectional externalities, it is essential that regulations take into consideration conversation programs in sensitive environments wholly, rather than pieces of isolated farmlands that spatially scattered. In essence, identifying, quantifying and managing externalities is essential in order to provide discernible means to accommodate their impacts. The subsequent section details some of these evaluation approaches.

\section{Valuation of (risk) externalities}

Accounting for (risk) externalities has been a topic of major concern as nations seek various means to find sustainable solutions to its related problems such as climate change. This has been the goal of the 2015 United Nations Climate Change Conference, COP 21 or CMP 11 held in Paris. The conference gave birth to the negotiation of the Paris Agreement, a global agreement on curbing down climate change and its consequences through mitigation and adaptation methods. These negotiations represent a consensus of the 196 parties attending the conference. The agreement is to become legally binding if joined by at least 55 countries which together represent at least 55 percent of global greenhouse emissions ${ }^{1}$ All these depict a strong signal of innovating ways towards sustaining current and future generations. In other words, it shows nations desire to avoid a catastrophic climate impact through so many discernible means such as a shift towards low-carbon economy.

There have been several arguments in relation to valuation of the externalities. In all these cases, internalization of risk externalities underscores the various debates. Hence, it is necessary to quantify the value of externalities in monetary terms through direct or indirect means. For instance, Bithas (2011) mention that in the real world where externalities prevail, their internalization or neutralization in the traditional way cannot lead to sustainability. In addition, the author highlights the fact that if internalization takes a very speci-

\footnotetext{
${ }^{1}$ For an overview see details of United Nations Climate Change Conference 2015
}

fic form that results in the inviolable preservation of environmental rights of future generations in pure biological terms, then, sustainability can be ensured. By and large, internalization of externality in its own right does not necessarily serve as a panacea to the problems cause by these externalities. Rather, it is dependent on the process of internalization. A way forward to attain sustainability with regards to internalization is to develop a robust method that encompasses the ethical concept and the techno-economical valuations. In this, both the present, and future generations that are directly and indirectly impacted by these externalities are adequately compensated. However, it might be a daunting task.

Furthermore, Klink (1994) provides insights into the ideas of Pigou and Coase, which have been at the core of internalizing externalities. Coase ideas are thought to be in support of negotiations between persons affected by different problems while Pigou is in favour of state intervention through taxation. A point of consensus of these two ideas is that Coase's recommendation coincides with the same policy implication of an accurate Pigouvian analysis. Thus, Klink (1994) underscores the fact that the combinations of beliefs among majority of economists made environmental issues to permeate the field of economics.

The theory of externality has been investigated by Vatn and Bromley (1997) along a set of conceptual problems, where they show that the two main traditional methods addressing externalities. That is, the Coasean and the Pigouvian are both vulnerable to the above critique. This still leaves one with the fact that the theory of externality is not yet well-settled and coherent at least from a theoretical point of view. A recent paper by Remig (2015) and the references therein, provide an excursion of the issues of sustainability and externalities in relation to efficiency because of its relevance for policy makers. Remig (2015) identifies several lapses in the current conceptual framework of externality and postulate that there should be a new definition, which considers complexity of interactions between social and environmental systems in the framework of Kallis and Norgaard (2015). In effect, all these could help provide a better formulation of sustainability economics in respect of sustainable development transformations.

\section{Empirical investigations in the con- text of (risk) externalities}

With an ever-increasing threats of climate change, despites efforts being taken to accommodate and curb down its impacts, studies on externalities are gaining ground in various discipline more than ever. In other words, finding a sustainable solution to the challenges that human beings and different sectors of the economy face, require appropriate internalization of externalities that occur at any point in time. Recent studies, therefore, attempt to explore externalities from empirical viewpoint. The perceived nature of nuclear risk as an externality led Welsch and Biermann (2016) to examine the 
relationship between Swiss citizens' life satisfaction (understood as a proxy of utility) and the proximity of their place of residence from the nearest power plant. In this paradigm, the concept of externalities from the perception of nuclear risk is related to the distance of residential areas from nuclear facilities. In view of this, the relationship between Swiss citizens' life satisfaction and the distance of their place of residence from the nearest nuclear power plant (NPP) has been estimated, where a statistically and economically significant satisfaction-distance gradient has been deduced. This gradient is smaller for citizens who anticipate some degree of protections due to wind direction and the topography of their residences. However, it differs from one individual to another by age, sex and one's level of education. These authors reiterated that the satisfaction-distance gradient has changed significantly after the nuclear disaster at Fukushima, Japan, indicating a reassessment of distance-dependent nuclear risk due to an information shock. It is, therefore, obvious that various factors such distance, access to information, an individual's characteristics and perceptions play a role in the determination of the extent of an externality and what constitutes it. Life satisfaction in most situation connotes happiness. A recent study, therefore, investigates and provide a new scale of externality of happiness beliefs: that is, the perception that one's level of happiness is controlled and tremendously depends on other external factors using two Korean and one Iranian sample data (Joshanloo (2017)). An individual's view on factors that determine happiness depend on various factors starting from internal factors (i.e effort, knowledge etc) and external factors such as life's situations, fate etc.

In another empirical framework, Bartczak et al. (2017) investigate the influence of energy price movements on the value people place on the avoidance of renewable energy externalities in Poland based on an individual's financial loss aversion and financial risk preferences via a choice experiment survey. An increase or a decrease in electricity bills is used to depict uncertain effect of new sources of energy generation on the current price level. Their findings indicate that that marginal utility of money seems to be lower with a rebate on the energy bill than with a surcharge. In effect, financial risk preferences affect people's choices both in cases: surcharge and rebate. However, loss aversion for money affects them just in the case of a rebate. With the global quest of a new world order, that is the change to a low carbon economy, this analysis provide a platform, which examine individual's consumption and investment behaviour coupled with potential uncertainties affecting the renewable energy development and their sustainability. Due to inequitable distribution of benefits of greenhouse gas emissions and the cost of mitigation and adaptation to climate change, Del Ponte et al. (2017) in an experimental economic framework show that people who willingly create climate problems, pass it on to others. However, it does not further worsen the situation of these other countries or individuals if there are in a distant geographical location. On the other hand, adverse impact from climate change make people more likely to invest and contribute to its mitigation.
On the other hand, Lin Lawell (2016) examines groundwater management and mentioned that the usage of groundwater and human behaviour could lead to over-extraction due to several factors, which includes increase irrigation, disincentives due to policy, institutional incentives and externalities. In case of externalities, the causal factor, be it the physical movement of water, environmental damages or benefits, or by other factors, a well-proven policy can provide the incentives to move an individual's extraction path back to the socially optimal one. However, in practice, it is worth noting that not all policies induce the socially optimal rate of extraction and thus demands that policy-makers identify any foreseeable disincentives to their policies. Most of the empirical analysis have been carried out in a laboratory setting due to constraint on real-world data. Other empirical studies on (risk) externalities include: Weber et al. (2016), Sovacool et al. (2016), Dementyeva and Verhoef (2016) and many more. Whilst current research work in this domain are very little, real-life situations are prevalent and hence requires further empirical research.

\section{Concluding remarks}

This paper provides and investigate current deliberations on a major topical issue; (risk) externalities, which permeates various sectors of the economy. However, it largely focusses on environmentally related externalities, thereby, providing the epistemological dimension of knowledge and deliberation in the context of (risk) externalities from both a theoretical and empirical point of view. As a result, this article examines the various types of externalities, which gives credence to the type of externalities that might exist at any point in time and the forms they make take. Therefore, externalities can be put into two broad categories namely: (i) positive externality and (ii) negative externality. In most cases, externalities are characterized by the process that give rise to them. However, some externalities do benefit economic actors at the same time having negative and detrimental impact on other economic actors.

In effect, the externality that emerges as a result of mitigating its risk is termed risk externality. Because of this, risk externalities are higher when economic actors are limited in their risk reduction provisions for the following reasons: (i) any spillover arising from the failure to accommodate all forms of risk as a result of economic activity are likely to affect other economic actors, (ii) when all economic actors fail in their bid to curb down risk impacts, the cost of all detrimental effects are higher. On the one hand, market failure leads to externalities of various forms and thus constitute a source of inefficiency. On the other hand, resolving the issue of market failure give rise to efficient economy. This resolution could take the form of internalization of externalities or a complete implementation of enforceable property rights. The latter is, however, a very difficult task to undertake in comparison to the former.

The findings of this paper suggest that the cost of risk 
transfer increases when agents in an economy are alike and thus give rise to higher risk externality as well expensive risk mitigation programs and other risk reduction activities. Tradition valuations of externalities is seen to attract a lot of discrepancies in the existing literature. Specifically, both the Coasean and Pigouvian approaches still have their shortcomings and are not coherent from a theoretical point of view. In addition, empirical valuation approaches are limited due to the difficulty in procuring these types of data. It, therefore, hinges on the fact that the way forward to attain sustainability and provide proper valuation methods is to design a robust method that encompasses the ethical concept and the techno-economical valuations - in that way both present, and future generations that are directly and indirectly impacted by these externalities are adequately compensated. In addition, empirical application should be high on agenda for future research.

\section{Acknowledgments}

This is a revised version of the paper: "A survey on risk externalities", Technical report no. 23, ECCUITY Project, Leuphana University of Lüneburg, and I am grateful to all the participants of the project: "Economics of Climate Change: Distribution, Efficiency, and Policy under Uncertainty" (ECCUITY). In addition, I am very much thankful to Stefan Baumgärtner, Wolfgang Buchholz, Martin Quaas and anonymous referees for their critical readings and comments of the paper; and to the German Federal Ministry of Education and Research for financial support under grant 01LA1104A.

\section{Conflicts of interest}

The author declares no conflict of interest.

\section{References}

[1] Alonso-Carrera, J., J. Caballé, and X. Raurich (2004). Consumption externalities, habit formation and equilibrium efficiency*. The Scandinavian Journal of Economics 106(2), 231-251.

[2] Andres, L., B. Briceño, C. Chase, and J. A. Echenique (2017). Sanitation and externalities: evidence from early childhood health in rural india. Journal of Water Sanitation and Hygiene for Development 7(2), 272289.

[3] Baumol, W. J. and W. E. Oates (1988). The theory of environmental policy. Cambridge university press.

[4] Baumgärtner S. and Fianu E. S. (2015). Risk, externalities, and Insurance, The 21st Annual Conference of the European Association of Environmental and Resource Economists (EAERE) and Technical Report No. 18, Leuphana University.

[5] Bartczak, A., S. Chilton, M. Czajkowski, and J. Meyerhoff (2017). Gain and loss of money in a choice experiment. the impact of financial loss aversion and risk preferences on willingness to pay to avoid renewable energy extarnalities. Energy Economics.

[6] Bhattacharyya, S. C. (2011). Energy economics: concepts, issues, markets and governance. Springer Science \& Business Media.

[7] Bithas, K. (2011). Sustainability and externalities: Is the internalization of externalities a sufficient condition for sustainability? Ecological Economics 70(10), 1703-1706.

[8] Capitanio, F., F. Adinolfi, and F. G. Santeramo (2014). Crop insurance subsidies and environmental externalities: evidence from southern italy. Outlook on AGRICULTURE 43(4), 253-258.

[9] Chipman, J. S. and G. Tian (2012). Detrimental externalities, pollution rights, and the coase theorem?. Economic Theory 49(2), 309-327.

[10] Choi, P.-S., A. Espínola-Arredondo, and F. MuñozGarcía (2017). Conservation procurement auctions with bidirectional externalities. Journal of Environmental Economics and Management.

[11] Delpierre, M., B. Verheyden, and S. Weynants (2016). Is informal risk-sharing less effective for the poor? risk externalities and moral hazard in mutual insurance. Journal of Development Economics 118, 282-297

[12] Del Ponte, A., A. W. Delton, R. Kline, and N. A. Seltzer (2017). Passing it along: Experiments on creating the negative externalities of climate change. The Journal of Politics 79(4), 000-000.

[13] Dementyeva, M. and E. T. Verhoef (2016). Miles, speed, and technology: Traffic safety under oligopolistic insurance. Transportation research part B: methodological 86, 147-162.

[14] Dupor, B. and W.-F. Liu (2003). Jealousy and equilibrium overconsumption. American economic review, 423-428.

[15] Hayes, R. (2016). Textbox: Internalizing externalities: Techniques to reduce ecological impacts of food production. In International Food Law and Policy, pp. 359-363. Springer.

[16] Joshanloo, M. (2017). Mediators of the relationship between externality of happiness and subjective wellbeing. Personality and Individual Differences 119, 147151 . 
[17] Lin Lawell, C.-Y. C. (2016). The management of groundwater: Irrigation efficiency, policy, institutions, and externalities. Annual Review of Resource Economics 8, 247-259.

[18] Kallis, G. and R. B. Norgaard (2010). Coevolutionary ecological economics. Ecological Economics 69(4), 690-699.

[19] Klink, F. A. (1994). Pigou and coase reconsidered. Land Economics, 386-390.

[20] Liu, W.-F. and S. J. Turnovsky (2005). Consumption externalities, production externalities, and long-run macroeconomic efficiency. Journal of public economics 89(5), 1097-1129.

[21] Luenberger, D. G. (1995). Externalities and benefits. Journal of Mathematical Economics 24(2), 159-177.

[22] Owen, A. D. (2004). Environmental externalities, market distortions and the economics of renewable energy technologies. The Energy Journal, 127-156.

[23] Remig, M. C. (2015). Unraveling the veil of fuzziness: A thick description of sustainability economics. Ecological Economics 109, 194-202.

[24] Shafran, A. P. (2008). Risk externalities and the problem of wildfire risk. Journal of Urban Economics 64(2), 488-495.

[25] Smith, V. K. (1974). Intertemporal production externalities, technical change, and public expenditure analysis. Journal of Environmental Economics and Management 1(2), 121-131.

[26] Sundqvist, T. (2004). What causes the disparity of electricity externality estimates? Energy Policy 32(15), 1753-1766.
[27] Taylor, M. H., L. Christman, K. Rollins, et al. (2013). Risk externalities, wildfire hazard, and private investment to mitigate wildfire risk in the wildland-urban interface. Technical report.

[28] Turnovsky, S. J. and G. Monteiro (2007). Consumption externalities, production externalities, and efficient capital accumulation under time non-separable preferences. European Economic Review 51(2), 479-504.

[29] Varian, H. R. (1992). Microeconomic analysis.

[30] Sovacool, B. K., M. A. Munoz Perea, A. V. Matamoros, and P. Enevoldsen (2016). Valuing the manufacturing externalities of wind energy: assessing the environmental profit and loss of wind turbines in northern europe. Wind Energy 19(9), 1623-1647.

[31] Vatn, A. and D. W. Bromley (1997). Externalitiesa market model failure. Environmental and Resource Economics 9(2), 135-151.

[32] Weber, J. G., N. Key, and E. ODonoghue (2016). Does federal crop insurance make environmental externalities from agriculture worse? Journal of the Association of Environmental and Resource Economists 3(3), 707-742.

[33] Welsch, H. and P. Biermann (2016). Measuring nuclear power plant externalities using life satisfaction data: A spatial analysis for switzerland. Ecological Economics $126,98-111$.

[34] 2015 united nations climate change conference, Wikipedia: https://en.wikipedia.org/wiki/ 2015_United_Nations_Climate_Change_ Conference

[35] Zerrahn, A. (2017). Wind power and externalities. Ecological Economics 141, 245-260. 